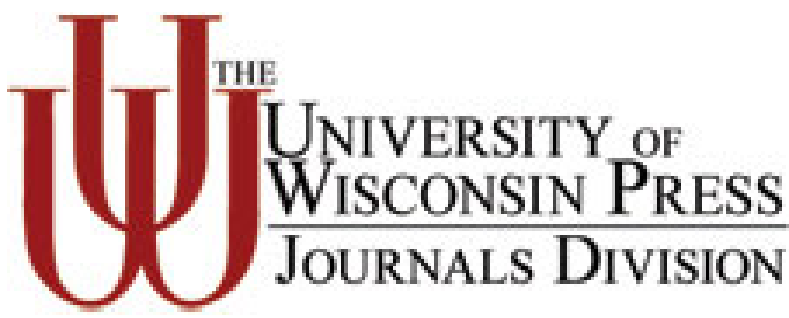

Dissolving the State: Three Recent Perspectives on International Relations

Transnational Relations and World Politics by Robert O. Keohane; Joseph S. Nye,; The Essence of Decision: Explaining the Cuban Missile Crisis by Graham Allison; Political Leadership and Collective Goods by Norman Frohlich; Joe A. Oppenheimer

Review by: R. Harrison Wagner

International Organization, Vol. 28, No. 3 (Summer, 1974), pp. 435-466

Published by: University of Wisconsin Press

Stable URL: http://www.jstor.org/stable/2706301

Accessed: 25/03/2014 13:42

Your use of the JSTOR archive indicates your acceptance of the Terms \& Conditions of Use, available at

http://www.jstor.org/page/info/about/policies/terms.jsp

JSTOR is a not-for-profit service that helps scholars, researchers, and students discover, use, and build upon a wide range of content in a trusted digital archive. We use information technology and tools to increase productivity and facilitate new forms of scholarship. For more information about JSTOR, please contact support@ jstor.org. 


\title{
DISSOLVING THE STATE: THREE RECENT PERSPECTIVES ON INTERNATIONAL RELATIONS
}

\author{
R. Harrison Wagner
}

Robert O. Keohane and Joseph S. Nye, Jr., eds. Transnational Relations and World Politics. Cambridge, Mass. : Harvard University Press, $1972.428 \mathrm{pp}$.

Graham Allison. The Essence of Decision: Explaining the Cuban Missile Crisis. Boston: Little, Brown \& Co., 1971. 338 pp.

Norman Frohlich, Joe A. Oppenheimer, and Oran R. Young. Political Leadership and Collective Goods. Princeton, N.J.: Princeton University Press, 1971. 161 pp.

This may seem at first an odd collection of works to be considered together. One was originally a special issue of International Organization, and is therefore chiefly a collection of articles. ${ }^{1}$ Another is a book about political leadership and does not treat international relations explicitly at all. Only one, in fact, is a straightforward book de-

R. Harrison Wagner is a member of the Department of Government at the University of Texas at Austin. This review essay arose out of work the author did during the academic year 1971-72, when he held a Ford Foundation Faculty Research Fellowship; during that time he was a research associate at the Center for International Affairs at Harvard University, and participated in the Study Group on Transnational Relations and World Politics organized there by Robert Keohane and Joseph Nye. Much of what the author has to say has been influenced by the discussions of that group, in many of which Graham Allison also participated. The subject of the author's own research during that year was the application of formal decision theory to the study of foreign policymaking. This essay is partly the result of his effort to interpret the discussions of this group in light of his own research at the time, and partly the result of an effort to get straight in his own mind what he had learned from the six people whose works it discusses.

${ }^{1}$ Robert $\mathrm{O}$. Keohane and Joseph S. Nye, Jr., eds., International Organization 25 (Summer 1971). All page references will be to the journal edition (not to the book). 
voted to the subject of international relations. Moreover, these works represent quite different levels of abstraction. One is chiefly a set of concepts and categories around which a group of articles reporting on various aspects of international relations has been organized. Another is an analysis of three different types of accounts that are claimed to be possible of a significant event in international politics. And the other develops a highly formal deductive theory.

In spite of their diversity, however, all these works can be said to speak to the same underlying problem, and each discusses matters that are relevant to the others. They all raise questions about the assumptions underlying the bulk of the literature that purports to explain what happens in international politics. Chiefly these are questions about the identity of the main actors in international politics and the regularities that characterize their behavior. However, these questions lead, in turn, to many other questions about how we are to understand strategic interaction among governments, the degree of interdependence that can be said to exist among them, whether, to what extent, and how the people of one nation can be said to exploit those of another, ostensibly independent nation, how one is to describe and explain international integration, the relation between international politics and international economic transactions, and many other fundamental issues in the study of international relations. Considered together, these questions also raise other serious questions about the role of empirical theory in the study of international relations. To some extent, these latter questions are raised implicitly by the differences in levels of abstraction exemplified between them. However, these questions are also discussed explicitly, especially in the Allison volume.

The problem of the identity and character of the main actors in international politics is raised explicitly in two of these works, and implicitly in the third. The volume edited by Keohane and Nye is, in part, an attack on what they call the "state-centric" model of international politics, by which they mean models that assume that international politics consists entirely of the relations between unified governments, that it is only the decisions of such governments that one needs to explain, and that in explaining their decisions the only nondomestic factor one needs to take into account is the decisions of other governments. The book by Graham Allison is less clearly an attack on any particular view. However, the best name for the first model of explanation that he discusses seems to me to be the state-as-actor model, although he does not call it that. And since the bulk of the book constitutes an effort to show how two other models can be used to increase one's ability to explain and predict the de- 
cisions of governments, it does not seem to me unfair to say that his book is a somewhat muted attack on state-as-actor accounts of international politics. Finally, the work of Frohlich, Oppenheimer, and Young does not explicitly attack any particular view of international politics. However, it does raise implicitly some questions about international politics very similar to the ones raised by Keohane and Nye and by Allison. Some of these questions are developed in Frohlich and Oppenheimer's Ph.D. dissertation, which will be discussed here as an extension of the book they wrote with Oran Young. ${ }^{2}$

There are really two assumptions at stake here: that governments are the only important actors in international politics, and that governments are unitary actors, that is, that one can usefully ascribe to them at least some of the characteristics of purposiveness and choice ascribed to persons. Keohane and Nye wish to attack both assumptions; Allison is interested only in the latter. Although Keohane and Nye use the term state-centric model to refer to both assumptions, I find it convenient to use it to refer solely to the first (the assumption that governments are the only important actors), and to use the term state-as-actor model to refer to models employing the second assumption (that states are unitary actors). This makes it easier to refer to the two assumptions separately; I hope it does not lead to confusion about the contentions of Keohane and Nye.

The literature on international relations is not dominated by any general consensus concerning the dimensions of the subject or the appropriate mode of analysis. Consequently, any effort to criticize it is open to the charge that one is attacking a straw man. However, a good case can be made for the view that the two assumptions under attack here have been the most important starting points for serious analysis in the field, and that they underly much, though certainly not all, of the empirical work done in it. I believe that an understanding of why these assumptions have been so important can also help one understand why they have not dominated the field entirely.

These two assumptions are commonly employed by writers who emphasize the anarchic character of international politics as the most important explanation of the behavior of states. Writers in this tradition frequently wish to insist on the permanence of certain characteristics of international politics that are frequently underemphasized by the representatives of subnational or transnational interests (for example, liberals or Marxists). The basic point of their

${ }^{2}$ Norman Frohlich and Joe A. Oppenheimer, "An Entrepreneurial Theory of Politics” (Ph.D. dissertation, Department of Politics, Princeton University, 1971). 
analysis, which is not always expressed in exactly the same way, is that international politics, because of mutual insecurity and the absence of superior political authority, is characterized by a constant danger of war. So long as subnational or transnational groups desire to maintain independent governments, they must reconcile themselves to the maintenance of these characteristics of international politics and take them into account in advocating policies for their governments. However, in doing so they will find they need to abandon some of their objectives that prove to be inconsistent with the need to secure their own government from military defeat.

By focusing on the presumed common objective of maintaining the autonomy of governments against the danger of military defeat, it is an easy step to the assumption that all governments are internally united by a desire for military security and externally preoccupied with threats to it. And this assumption makes more plausible the notion that governments are the only important actors in international politics. Unfortunately, neither proposition is strictly implied by the notion of international anarchy. This assumption is, however, a seductive step, and many take it without thinking about it critically. Moreover, it is rhetorically convenient to take such a step, because writers in this tradition find themselves resisting the tendency of others to ignore these features of international politics, or wish them away, and any other assumption would make this task more difficult. However, because these assumptions are not strictly necessary for this sort of analysis, a variety of other research emphases have never been considered inconsistent with it.

There is also another reason to take this step. It is often assumed, implicitly or explicitly, to be a theoretically productive simplification. By concentrating on relations between governments, some scholars have clearly hoped to be able to develop a model of international politics that, while not necessarily completely accurate as a description, would nonetheless capture its basic features. The example of economics has sometimes been influential, along with the theory of games, in encouraging such ambitions. An emphasis on the idiosyncrasies of policy formation in individual countries can seem merely a way of muddying the waters, much as an emphasis on the process of decision making in individual firms seems to many students of microeconomics. Even when international relations scholars' theoretical goals were neither as explicit nor as ambitious as those of economists, an analysis of international politics in these terms could seem a necessary and entirely legitimate simplification of reality. Allison's discussion of what he calls Model I, and what I call the state-as-actor model, makes clear this function of such an approach. 
However, Allison's discussion does not make clear two serious deficiencies of such an assumption as an effort at theoretically fruitful simplification. The first is that, in comparison with microeconomics, ascriptions of particular goals to governments seem uncomfortably ad hoc. Objectives such as power and military security prove on examination to be either unacceptably vague or empirically inadequate. Moreover, if questions can be raised about the justification for assuming that business firms seek exclusively to maximize profits, far more serious questions can be raised about the ascription of any particular goal to governments.

A second difficulty has been that whatever goals are ascribed to governments, it has not proved easy to construct theories on the basis of such assumptions. It has become clear that the problems of international politics are analytically similar to the problems of oligopoly in economics and of $\mathrm{N}$-person variable-sum games in the theory of games, and that these problems do not immediately lend themselves to determinate theoretical solutions. Although it would be wrong to say that theories in this area have been unhelpful, nonetheless the whole area is sufficiently untidy, and sufficiently dependent on knowledge of the peculiarities of concrete situations, to fail to offer a very powerful inducement to indulge in the simplification implied by the stateas-actor assumption and its frequent companion, the state-centric assumption.

Thus in spite of the strong forces supporting these assumptions, their defects have prevented them from sweeping the field entirely, and one can find many treatments of internal political processes and transnational forces and actors in the literature. But the relation between these parts of the literature and the parts based on the assumptions in question has never been entirely clear, and scholars have tended to move fleetingly from one sort of analysis to another, often without noticing the change themselves. The study of the domestic roots of foreign policies, or of transnational actors, has never been fully integrated with efforts to provide some intelligible account of the workings of the international system. The main exceptions to this statement have been the literature on international political integration, on the one hand, and Marxist analyses of international politics, on the other. Apart from this literature, most attempts to develop some sort of general picture of the workings of international politics employ the state-centric and state-as-actor assumptions; and in spite of the fact that attention has been paid to other factors, it is relevant to ask how a systematic integration of them into our picure of the system as a whole would alter our understanding of international politics. 
II

Having said this, it becomes relevant to ask what the relation is between these two assumptions. Clearly they can be altered independently of each other. I think that Keohane and Nye are right to suggest that the consequences of relaxing them both simultaneously may be especially interesting. However, their suggestion raises some important questions about what to substitute for the state-as-actor assumption.

Keohane and Nye outline their new approach to the study of international politics in the preface and conclusion of the volume they have edited. (They have, incidentally, been unusually successful in persuading the authors of the articles that lie in between to conform to the guidelines and address themselves to the questions implied by this new approach.) By and large, the preface is an attack on the state-centric assumption: it argues for the need to include relations among nongovernmental actors as part of the analysis of international politics; hence the term transnational relations. In the conclusion the state-as-actor assumption is also relaxed, although in a rather ad hoc way. However, even in the preface there is some discussion of transnational influences that implies some disaggregation of the state, although it is not clear what kind.

Clearly the effects of talking about transnational relations with the state-as-actor assumption and without it are quite different. If one assumes that states are unitary actors, then one concentrates on the role of nongovernmental entities (e.g., the multinational corporation) as actors in international political conflicts, bargaining with and otherwise influencing both each other and governments. If one drops this assumption, then it becomes possible for individuals and groups to participate directly in the decision-making processes of more than one state, rather than simply to bargain with them or otherwise influence the consequences of governmental actions. Moreover, other sorts of transnational influences on national decision making, such as information flows and socialization processes, become subjects for investigation as well.

Unfortunately, Keohane and Nye not only do not discuss carefully the effects on their analysis of various ways of dropping the stateas-actor assumption but also do not distinguish very carefully between these various types of transnational influences. They lump together under the generic term transnational relations all types of relations in which nongovernmental actors participate. As a result, the immediate effect of their new paradigm is to dissolve the traditional actors in international politics into shifting and poorly defined 
components and to embed them in a set of poorly differentiated transnational relationships.

These ambiguities lead to some uncertainty about the nature of the assertions they make about international politics, and the research program they derive from their new paradigm. For example, they claim that attention paid to transnational relations will lead to explanations of governmental decisions that are different from those the state-centric model leads to, and that transnational relations are becoming more important. Unfortunately, their argument can also be construed as implying no more than a shift in our attention to new areas of international politics (e.g., economic issues), where transnational relations have always been studied but which have not been at the center of attention of political scientists. And it is not clear whether the world has really changed in the direction claimed or whether we have just overlooked some things all along. Which of these views one adopts, and what types of transnational relations one focuses on, may depend on what one does with the state-as-actor assumption.

In their preface, Keohane and Nye introduce their paradigm with a number of important definitions. They define global interactions as "movements of information, money, physical objects, people, or other tangible or intangible items across state boundaries." They then define transnational interactions as the "movement of tangible or intangible items across state boundaries when at least one actor is not an agent of a government or an intergovernmental organization." 3 They clearly intend to employ a net large enough to capture almost any variety of influence on human behavior that cuts across national boundaries, without at this point distinguishing very carefully between them.

At a later point they resist another opportunity to make some analytical distinctions. After having argued that their paradigm requires a broader definition of politics than one confined to intergovernmental relations, they adopt an extremely broad replacement: "We therefore prefer a definition of politics that refers to relationships in which at least one actor consciously employs resources, both material and symbolic, including the threat or exercise of punishment, to induce other actors to behave differently than they would otherwise behave." ${ }_{4}$ This is not an unusual definition. It does, however, have the unfortunate effect of defining politics to mean almost any sort of social relation. One striking result of taking such a defini-

${ }^{3}$ Keohane and Nye, p. 332.

${ }^{4}$ Keohane and Nye, p. 344 . 
tion seriously would be to incorporate all of international economics, without, to all appearances, any of its theoretical apparatus, into the definition's scheme. It is not clear that this would represent an intellectual advance. (From the examples they present and the contentions they make, it sometimes appears that what really interests them is a much narrower definition of politics, defined as something like bargaining or strategic interaction. But this is not always entirely clear.)

With this definition in mind, Keohane and Nye list five major effects of transnational interactions on recent international politics. First, they state that transnational interactions may have led to attitude changes in the people who have participated in them or been affected by them which have important consequences for state policies. A second effect has been the "promotion of international pluralism, by which we mean the linking of national interest groups in transnational structures, usually involving transnational organizations for purposes of coordination." A third effect is "the creation of dependence and interdependence" among governments. ${ }^{5}$ This may mean, simply, that the success of government policies depends on transnational forces that no single government can control completely but that more than one government tries to influence. However, a fourth effect is the creation of new instruments that one government may use to influence others, as, for example, the efforts of the American government to make use of private investors to support its foreign policy objectives abroad. Finally, a fifth effect is the emergence of nongovernmental international actors, in their own right, with "private foreign policies that may deliberately oppose or impinge on state policies." 6

At least the first two of these effects assume some disaggregation of the state. However, at this point there is no explicit treatment of the state-as-actor assumption or any alternative to it. In the conclusion, Keohane and Nye turn their attention explicitly to this assumption. But they treat it in an extremely narrow way that has no clear relation to the effects mentioned in the preface. What they say in the conclusion does, however, give rise to some of the most interesting contentions they make. Because it is heavily dependent on Graham Allison's work, it will lead us directly to an examination of his book.

What Keohane and Nye say is best said in their own words.

There is another dimension of world politics that the classic state-centric paradigm with its assumption of states as unitary

\footnotetext{
${ }^{5}$ Keohane and Nye, pp. 338-39. Emphasis in orginal.
}

${ }^{\circ}$ Keohane and Nye, p. 337. 
actors fails to take into account. This second dimension, centralization of control, involves the realization that subunits of governments may also have distinct foreign policies which are not all filtered through the top leadership and which do not fit into a unitary actor model. Thus, scholars have recently developed a "bureaucratic politics approach" to foreign policy analysis, explaining decisions of governments in these terms.

Thus their only explicit treatment of the state-as-actor assumption consists almost entirely of absorbing into their paradigm the literature on bureaucratic politics. As a result, they are able to suggest the possibility of what one may call transnational bureaucratic politics and what they call "transgovernmental interactions," that is, the extension across national boundaries of the process of bargaining and coalition formation between bureaucrats and bureaus that students of this process claim to be the stuff of which foreign policies are made. It becomes possible, in this view, for bureaus in two different governments but with similar policy interests to concert their actions in such a way as to influence the official policies of both governments. As I suggest below, this may be the most interesting possibility suggested by the arguments of Keohane and Nye, and the most subversive of established patterns of thought and analysis.

On the basis of these definitions and observations, and of the research reported in the substantive articles that lie between the preface and conclusion, Keohane and Nye advance a tentative program of research.

We are suggesting an approach to the study of world politics through analysis of different types of issue areas (which we define loosely, following Cox, as unorganized or partially organized systems of interaction) and of the relationships between them. The elaboration of this paradigm suggests three foci for research: 1) analysis of issue areas, 2) research on transnational and transgovernmental actors, and 3) studies designed to illuminate relationships between issue areas. ${ }^{8}$

At the basis of their research proposal is the assumption, which they do not justify explicitly, that international politics is divided up into more or less discrete issue areas, the relations between which are problematical. This is a conception that makes sense; but it is strikingly different from the conception of someone like Hans Morgenthau, for whom all elements of national policies are related to the overarching concern of national governments-power, or, as some would

\footnotetext{
${ }^{7}$ Keohane and Nye, p. 731.

${ }^{8}$ Keohane and Nye, p. 734.
} 
prefer, security. It is also different from much of the economics literature, which is concerned with analyzing the ways in which various instruments of foreign economic policy interact to affect such possible national goals as the maximization of national income. It is a conception that can be derived from the relaxation of the two assumptions under discussion here: relatively independent government agencies seek to maintain their autonomy and influence by denying to others any influence over the subgoals with which they are charged; and different constellations of interest groups, both national and transnational, grow up around these subgoals and have some interest in maintaining the boundaries that separate them from other areas of government action.

Once one abandons these two assumptions, then, relations between issue areas can become problematic, and therefore open to empirical investigation. What Keohane and Nye are proposing is that this sort of inquiry be joined with an analysis of the nature of the actors, both governmental and nongovernmental, and of the patterns of interaction that characterize each issue area.

A little reflection suggests, however, that the way the stateas-actor assumption is relaxed may be as important as an emphasis on nongovernmental actors in defining Keohane and Nye's research program and understanding its significance. The national security issue area, for example, has been at the center of the study of international politics from the beginning. Presumably the main result of relaxing the state-centric assumption alone would be to focus attention on transnational actors in this issue area. But what would they be? Communist parties and other international political movements? The formal and informal organizations that have attempted to steer all the governments of Europe toward political integration during the postwar period? Yet these are actors that have not really been ignored by students of international politics, and not many others leap readily to mind. Moreover, on occasion Keohane and Nye seem to suggest that the security issue area is one in which transnational relations are least important. ${ }^{9}$

In the issue areas traditionally studied by economists, however, no one has ever doubted that transnational relations were important. Indeed, a case can be made for saying that not enough attention has been paid to the problem of explaining the policies of governments in these areas. ${ }^{10}$ One could as easily argue that what is needed is more

\footnotetext{
${ }^{9}$ See, for example, Keohane and Nye, p. 728.

${ }^{10}$ Compare Benjamin J. Cohen, "American Foreign Economic Policy: Some General Principles of Analysis," in American Foreign Economic Policy: Essays and Comments, ed. Benjamin J. Cohen (New York: Harper \& Row, 1968), Part I.
} 
state-centric analysis by economists, just as more emphasis on transnational relations by political scientists is needed. Here the main effect of political scientists' abandoning the state-centric assumption would be to direct our attention to the political conflicts associated with these issues and to the relation between them and other issues, for example, security issues. But the Keohane-Nye paradigm does not really say anything about the analytical problems involved in such an enterprise, and, as I said earlier, it is not clear what place the theoretical work of international economists has in their scheme.

In short, to make the discipline of international politics take account of all the conflicts that exist between governments in some coherent and well-integrated fashion would, indeed, transform that field, and this would be a very desirable development. But it is not clear that this would necessarily require any really novel emphasis on nongovernmental actors; nor is it clear that it requires a new paradigm of analysis. It may develop, of course, that a new paradigm is required to handle areas of policy that were not formerly at the center of the study of international politics; but, in that case, it would have to be some paradigm other than the one presented in this volume, since that consists mainly in defining and calling attention to the existence of a variety of transnational relations.

This leaves us, then, with what I have already suggested is the main novelty of the analytical enterprise of Keohane and Nye: the suggestion that bureaucratic politics takes place across national boundaries. This is most easily shown in nonsecurity areas, and instances are to be found in this volume. However, in an earlier article Keohane has shown how this is possible even in the security area, at least in relations between the American government and its smaller allies. ${ }^{11}$ If this can be shown to be a general phenomenon, it would fundamentally alter many conceptions of alliance relations between non-Communist countries, and would thus attack the traditional paradigm on its home ground.

But this suggestion derives as much from how the state-as-actor assumption is relaxed as from the contention that states are not the only actors in international politics. Moreover, it is based explicitly on Allison's work, and thus leaves open the possibility that another way of disaggregating the state would lead directly to other types of transnational relations that would be as subversive of the traditional paradigm as this one is. One thinks immediately of the other forms of transnational relations mentioned by Keohane and Nye that imply some disaggregation of the state, but their concentration on

11 "The Big Influence of Small Allies," Foreign Policy 1 (Spring 1971) : 161-82. 
Allison's analysis apparently does not permit them to pursue these. At this point, then, it may be useful to focus more directly on the state-as-actor assumption, and the work of Graham Allison.

III

Allison's book examines what he claims to be three different paradigms, or models, relevant to explaining the foreign policy decisions of governments. Model I considers governments as actors with purposes, choosing courses of action designed to achieve them; it is meant to represent the standard assumptions of much traditional international relations literature. Under this heading Allison discusses one particularly stringent set of assumptions about purposive actors-those assumptions that are generally grouped under the heading of rationality. Unfortunately, a careful reading will show that the relation between explanations that assume rational behavior and purposive explanations with less stringent assumptions is not made entirely clear in Allison's account.

Models II and III are introduced as promising alternatives to the standard view. Model II considers governments as large, complex organizations operating according to complex sets of routine and standard rules of behavior; it is based primarily on Cyert and March's Behavioral Theory of the Firm, and includes a discussion of the critiques of the modern conception of rational choice that have been made by members of what may be called the "Carnegie Tech" school of organization theory. Model III considers governments as coalitions of semi-independent policymakers, and it views government decisions as being the result of a process of bargaining and coalition formation between them which has acquired the name bureaucratic politics. It is based primarily on the political science literature, with the work of Richard Neustadt as the main inspiration. Each of these three models, or conceptual frameworks, is used in turn as the basis of an analysis of the Cuban missile crisis.

Allison's book is a much more elaborately developed theoretical exercise than the Keohane-Nye paradigm. It may, in fact, be the most generally persuasive attempt ever made to show the relevance of theorizing to the treatment of what are ordinarily thought to be the main problems of the study of international politics. Its general appeal is primarily due to the effectiveness of Allison's theoretical arguments in his analysis of the Cuban missile crisis, which contains a number of striking insights and some information that no one else had thought to look for. The results are a much more complex analysis of that event than anyone else has offered and a radically different 
understanding of what happened from the one most people had previously adhered to. To the extent that these considerable virtues are the direct result of Allison's reflections on the theoretical literature mentioned, they seem to be the product of his efforts to make these three paradigms as explicit as possible, enabling him to derive as much insight from the assumptions of each as he could, and to develop alternative explanations for this event, which had the heuristic effect of leading him to look for possibilities that had not occurred to analysts more nearly the prisoners of a single, and poorly articulated, set of assumptions. These are, I think, among the important benefits to be derived from explicit theory construction, and Allison's example is therefore one well worth taking seriously.

My main concern here is with Allison's account of his three models, and the theoretical literature on which they are based, since his book is one of the most influential recent treatments of the state-asactor assumption and its alternatives. Although I think that Allison's book fully deserves the acclaim it has received, I want to suggest that there are some problems with his treatment of these issues. Discussion of these problems is, I think, especially relevant to the questions raised by Keohane and Nye, on the one hand, and the collective goods literature (to be discussed below), on the other.

The first problem I want to mention is the fact that although Allison speaks of models, he mentions none in the sense of constructs yielding clear inferences that can be compared with the facts. Allison himself is quite clear on this point; however, his discussion can mislead the unsuspecting reader and lead to some confusion about the relation between these models. The Hempelian account of scientific explanation, which Allison follows, implies that one explains statements and not events - that explanation consists in showing that some statement about the world can be deduced from a statement of some regularity coupled with a statement to the effect that what one wants to explain was an instance of that regularity. In this view, it is quite misleading to speak of "explaining the Cuban missile crisis," the subtitle of Allison's book, since the Cuban missile crisis could be the subject or predicate of an indefinitely large number of statements, deducible from a great variety of explanatory schemes. Thus, it is possible that genuine models constructed along the lines of each of Allison's conceptual frameworks would imply statements about the Cuban missile crisis that were clearly inconsistent with each other. It is also possible that such models would be relevant to statements about the Cuban missile crisis that were entirely different and quite unrelated, except for the fact that they all were part of the series of events that customarily go by that name. In short, it is really not 
clear whether these are alternative explanations of the same thing or simply different explanations of different things. Allison discusses this point in a footnote on page 329 ; but my experience has been that many readers are left with the (justifiable) impression that one can construct three entirely different and equally valid, though not necessarily equally detailed, accounts of the same events, depending on one's point of view. Allison encourages this interpretation by speaking of "conceptual lenses," or "conceptual spectacles," which, like tinted glasses, determine how the world will appear.

Other readers, however, seem to have acquired the impression that the book demonstrates the superiority of one of three competing explanations: Model III, or the bureaucratic politics model. Yet this impression is unjustified. Thus, this confusion gives rise to considerable ambiguity as to what Allison's work implies for future research. Too few readers seem to have drawn what seems to me to be the main lesson, and one that I think Allison would not disagree with : that one must try to move from Allison's conceptual frameworks to genuine models.

However, if one wanted to do this, it is not at all clear why one would want to follow the guidelines of Allison's three models. Consider the constituents of each, and how they are distributed among them. Only Model II, the organizational process paradigm, includes a relatively clear-cut set of assumptions about the behavior of individual persons. The concept of rational choice is primarily a constituent of Model I, which I call the state-as-actor model. But for economists and decision theorists, rationality is a characteristic of individuals, and it is legitimate to ask for some account of how individual choices are aggregated in such a way as to produce a collectively rational result. Yet this forms no part of Allison's discussion of Model I. Model III, the bureaucratic politics model, contains no discussion of behavioral assumptions at all. Yet one could presumably construct a theory of bureaucratic bargaining based on the decision theorists' assumptions, and another theory based on Herbert Simon's. It is not clear which Allison has done. Thus it is not entirely clear whether Model III is independent of Model II or an extension of it; certainly bureaucratic bargaining seems to be constrained by many of the factors discussed under Model II, and many of Allison's readers seem to mingle the two together in speaking of the lessons of his book.

A related ambiguity in these models concerns the place of states of affairs in the international arena. These are discussed most explicitly in connection with Model I, although such conditions also appear at least implicitly as stimuli for the standard operating procedures discussed under Model II. But what of Model III? Are the 
participants in bureaucratic politics bargaining about competing means of achieving some overarching set of national objectives, or do they have such conflicting preferences about foreign policy that the result of the bureaucratic political process can best be considered a complex compromise between competing foreign policies? Although Allison says on occasion that Model I considerations enter into the preferences of players in the bureaucratic game, he does not clearly show how. Moreover, many of his readers acquire the understandable impression that the study of bureaucratic politics is somehow an alternative to an analysis of international politics along the lines of Model I, which is yet a different proposition.

Furthermore, Allison's discussion of Model I explanations that are based on the restrictive assumption of rationality is very limited; and as a result, he conveys a quite misleading impression of what would be required by an attempt to construct such explanations and the difficulties involved in doing so. He also exaggerates the extent to which one can legitimately say that such explanations are to be found in the literature. A fuller treatment of these problems could conceivably have led to a quite different account of the relation between Model I and Model II.

Contrary to the impression left by Allison's discussion, only a very small part of what he calls the "classical" literature on foreign policies and international politics is based on some explicit definition of rational choice. It may be that the writings of such people as Morgenthau, Hoffmann, Kissinger, and Aron can best be interpreted as employing some implicit notions of rational behavior. But it is far from clear that any of their main arguments could be sustained entirely by any acceptable, fully articulated model of rational choice, or would even be consistent with such a model. ${ }^{12}$ Nor is it clear that they are all inconsistent with the assumptions underlying Allison's Model II, which are closely allied to Herbert Simon's behavioral model of rational choice.

At the heart of the problem of constructing models of international politics (ignoring, for the moment, the problem of collective choice) are the related questions of how one should deal with uncertainty and with the fact that the decision problems of actors are interdependent-that what one decides depends on what the other decides, and vice versa. There is, as yet, no general agreement about the answers to these questions, but a reading of the relevant literature will show that it is by no means clear that the answers can be divided

\footnotetext{
${ }^{12}$ Compare William Riker's discussion of the balance of power in The Theory of Political Coalitions (New Haven, Conn.: Yale University Press, 1962), pp. 160-74.
} 
so neatly between Allison's Model I and Model II. For example, anyone reading Howard Raiffa's Decision Analysis in conjunction with the article on organizational decision making by Feldman and Kanter in the Handbook of Organizations would have a somewhat different impression of the relation between the domains of Allison's first two models than the one left by his account. ${ }^{13}$ The point, however, is not that some other account of this relation is superior but that it is misleading to say that there are two clearly different answers to the same question. The relation between the decision criteria underlying Allison's Model I and Model II is itself an important analytical problem, and Allison's account leaves a quite misleading impression of clarity.

Finally, one must consider the fact that both the classical theory of the firm, which is the basis for some of Allison's discussion of Model I, and the version offered by Cyert and March, which is the basis of Allison's Model II, are theories of market behavior. What is a government bureaucracy's counterpart to the market, and how easy is it to transfer concepts and theories from one sort of enterprise to the other? Anthony Downs's work on bureaucracies makes much of the distinction between firms and government bureaus. ${ }^{14}$ Downs also distinguishes between the behavior of bureaucrats and politicians, although these are conflated in Allison's Model III. Yet the relation between the two is a crucial matter. ${ }^{15}$ Consideration of these problems may lead one to conclude that the relation between bureaucratic politics and politics in the larger sense-voting, Congress, interest groups, and class conflict-is sufficiently close that the latter phenomena cannot simply be made the subject of some other model to be developed later, as Allison suggests, but must be an integral part of the analysis of the phenomena his book discusses. This is a view that Marxists may also be expected to agree with.

It would, indeed, be surprising if the political contexts in which bureaucracies operated had no effect on what goes on within them. The political context within which American bureaucratic politics

\footnotetext{
${ }^{13}$ Howard Raiffa, Decision Analysis: Introductory Lectures on Choices under Uncentainty (Reading, Mass.: Addison-Wesley, 1968); Julian Feldman and Herschel E. Kanter, "Organizational Decision Making," in James March, ed., Handbook of Organizations (Chicago: Rand McNally, 1965), pp. 614-49.

${ }^{14}$ Anthony Downs, An Economic Theory of Democracy (New York: Harper \& Row, 1957) ; and Downs, Inside Bureaucracy (Boston: Little, Brown \& Co. for the RAND Corporation, 1967). There is also some discussion of this problem in Cyert and March; see Richard M. Cyert and James G. March, A Behavioral Theory of the Firm (Englewood Cliffs, N.J.: Prentice-Hall, 1963), pp. 284-88.

${ }^{15}$ Compare Stephen D. Krasner, "Are Bureaucracies Important?," Foreign Policy, no. 7 (Summer 1972) : 159-79. Allison sometimes calls his Model III a "bureaucratic politics" model, and sometimes a "governmental politics" model. Some important questions turn on the difference.
} 
takes place is quite peculiar, and it may account for the fact that bureaucratic politics is so important in the United States. Thus the extension of Allison's Model III to other countries may be a less straightforward enterprise than he implies.

The general point that lies behind all these quibbles is that an effort to develop genuine models of foreign policy decision making would most likely lead not to further development of Allison's three models but to quite different constructs, and Allison explicitly recognizes this possibility. This point should not be surprising, because Allison's models are really just efforts to summarize the main features of three different bodies of literature. But since not much of that literature was written with the intention of developing formal theory, it would have been a quite unlikely coincidence that they should each provide the basis for three clearly distinct types of explanations of foreign policy decisions. It is therefore unfortunate that one of the effects of Allison's book, and an effect that does not do justice to the many qualifications and caveats to be found throughout it, seems to be to etch indelibly on the minds of many of his readers the outlines of these three models of explanation.

IV

So far I have discussed two approaches to international politics. One emphasizes that relations between governments are not the only international relations relevant to international politics, but it contains some ambiguities because of the way in which it treats governments and defines international politics. The second emphasizes what is to be learned by disaggregating governments and examining the sometimes disorderly process by which collective decisions are reached within them, but it disaggregates governments in ways that seem, on reflection, to be somewhat arbitrary. In recent years there has been increasing interest in the possibility of developing formal theories of political behavior in which the main properties of political systems are not assumed from the outset but are derived instead from assumptions about the behavioral characteristics of individuals, much as microeconomic theory attempts to infer propositions about markets from similar assumptions. Most such efforts, however, do incorporate some assumptions about political institutions, and assume as well the existence of only one polity. Consequently, international politics does not play a part in them. But, in principle, there is no reason why one could not develop a theory of international politics based on such assumptions. Such a theory would, in effect, relax the state-centric and the state-as-actor assumptions simultaneously and radically; 
neither governments nor national boundaries would appear in any form as assumptions in the theory.

One possible basis for such a theory is the economists' concept of collective goods, which is, in fact, the basis for an important body of economic literature on the functions of the state. ${ }^{16}$ It is from this part of economic theory that the work of Frohlich, Oppenheimer, and Young is derived. While not much of their work is explicitly devoted to international politics, they say enough to give one some idea of the broad implications of this type of theory for that subject. Thus, in discussing their work I am mainly interested in what it indicates about the relevance of a larger body of formal theory of increasing interest to political scientists and to students of international politics. It will become clear, I think, that this literature raises a number of questions similar to those already discussed. However, while it avoids some of the ambiguities that characterize the works already discussed, it does so by employing assumptions so restrictive as to raise questions about its relevance.

The notion of a collective good is often summarized as referring to that category of goods that if provided to anyone are simultaneously made available to everyone. Clean air, national defense, and public health programs are often introduced as examples. However, it has become clear that there are really two defining characteristics of such goods, and these characteristics can vary independently of each other. These two characteristics unfortunately do not go by standard names in the literature, which can lead to confusion. Because the names seem to me to be descriptive of the properties involved, I call them nonexclusiveness and nonrivalness of consumption. ${ }^{17}$

Nonexclusiveness simply means that it is not feasible to exclude persons from consumption of the good in question, and therefore it is not feasible to grant access to the good on a selective basis. As a result, it is not possible to charge a price for consumption of the good. Cleaning up the air in New York City is a good with this property.

Nonrivalness of consumption simply means that one person's consumption of the good does not significantly diminish the quantity available to another. Cleaning up the air in New York City also happens to exhibit this property, unlike, for example, eating loaves of

\footnotetext{
${ }^{16}$ Another possible basis, of course, is the theory of $\mathrm{N}$-person games. See, for example, Riker, pp. 211-43; and Anatol Rapoport, N-Person Game Theory: Concepts and Applications (Ann Arbor: The University of Michigan Press, 1970), pp. 303-7.

${ }^{17}$ This distinction was first made by J. G. Head, "Public Goods and Public Policy," Public Finance 17, no. 3 (1962) : 197-221.
} 
bread, the eating of one of which leaves exactly one loaf less available for others.

Each of these two characteristics has significant implications for the manner in which such goods are supplied, and together they raise questions about whether such goods will be supplied at all. The first characteristic implies that efforts to match each person's demand for the good with some contribution on his part toward its supply will be frustrated, because everyone has an incentive to misrepresent his preferences; the quantity of the good available to a person is not determined by his expressed preferences, but his contribution would be.

The second characteristic implies that the conditions for an optimal supply of the good in question are different from those of private goods. ${ }^{18}$ In the case of private goods supplied by a competitive market, individuals all pay the same price for the goods they consume and adjust the quantities they consume in accordance with their personal preferences. In the case of collective goods, however, they all consume the same quantity, and hence it is the price that each pays that must be adjusted to arrive at a social optimum. Moreover, the price to be paid by each is indeterminate: the only requirement implied by the notion of Pareto optimality is that there be no set of consumers of the good who, together, would be willing to contribute what it would cost to supply one additional unit of the good, however small. But this requirement is consistent with an infinite variety of ways in which the total costs of supplying the good might be shared among its recipients. The second characteristic, in other words, implies that there is a bargaining problem associated with the supply of such goods.

These two defining characteristics of a collective good are not only analytically distinct; they can also vary independently of each other. Moreover, each can vary continuously. That is, the first characteristic, nonexclusiveness, can actually range from complete nonexclusiveness at one extreme to completely individualistic access, as with private goods, at the other, with varying numbers of persons granted collective or individualistic access in between the two extremes. And nonrivalness of consumption can actually vary from complete nonrivalness at one extreme, where one person's consumption interferes not at all with another's, to complete rivalness, as with private goods, at the other extreme, where one person's consumption reduces another's by exactly the same amount. In between, each per-

\footnotetext{
${ }^{18}$ P. A. Samuelson, "The Pure Theory of Public Expenditure," Review of Economics and Statistics 36 (November 1954) : 387-89.
} 
son's consumption may interfere with others' by varying amounts. The independence and variability of these two characteristics are important to Frohlich and Oppenheimer's discussion of international politics in their dissertation. However, most of the literature on collective goods concentrates on the case that is the polar opposite of private, marketable commodities; therefore, it is necessary to focus on the problems associated with such "pure" collective goods first.

There are two problems posed by the characteristics of such pure collective goods. The first is how such goods are to be supplied at all. The second is how one may arrange for them to be supplied optimally.

It is clear that such goods will not be produced to be sold for profit, since they cannot be sold. It is also clear that they will not in general be supplied by individual persons seeking to satisfy their own needs, because for many important goods of this type no single person values them sufficiently to outweigh the cost. For example, who would clean up the air in New York City, even if he could, simply to satisfy his own desire for clean air? These considerations lead economists readily to the proposition that such goods can usefully be supplied by governments, whose taxing powers give them the ability to raise the requisite resources. From this point, attention is naturally shifted to the problem of how governments are to arrange for an optimal supply of such goods ; and this leads, in turn, to a discussion of the effects of various decision rules and the standards by which tax and expenditure policies should be judged.

There are two questions that are slighted by such a shift in emphasis, however. One is whether collective goods can be supplied in ways other than by governments. And the other is how one explains the existence of the political institutions invoked as the solution to the inability of the market to do this particular job. The existence of a government motivated to supply such goods is usually taken for granted; this is even true of Anthony Downs's work, critical though it is of standard assumptions in economics about the motivations of governments. It is out of an attempt to answer questions such as these that the work of Frohlich, Oppenheimer, and Young arises. However, since their work arose even more directly out of criticism of Mancur Olson's treatment of these problems, it is convenient to mention Olson's work first. ${ }^{19}$

Olson argues that many organizations provide collective goods to their members, that this is, for example, what interest groups are

${ }^{10}$ Mancur Olson, Jr., The Logic of Collective Action: Public Goods and the Theory of Groups (Cambridge, Mass.: Harvard University Press, 1965). 
set up to do. However, following most of the economics literature, he also argues that the ability of governments to supply such goods is based on their ability to tax, which allows them to overcome the difficulty of raising resources voluntarily. This raises a question about how nongovernmental organizations can successfully do the same thing. Olson's answer is an extension of the usual assumption about governments. If persons can be persuaded to part with resources under the threat of personal sanctions against them, they may also be persuaded to do so by personal inducements. Hence Olson argues that although members of small groups may agree among themselves to supply voluntarily the resources for collective goods, such cooperation becomes more difficult when the number of people involved becomes large; therefore, all large groups or organizations raise the resources necessary to supply collective goods to their members either through the imposition of sanctions, as with the union shop in the case of labor unions, or through the sale of private goods, as with the sale of group life insurance and other goods by interest groups.

The work of Frohlich, Oppenheimer, and Young is based upon a disagreement with this part of Olson's argument. There are two parts to their thesis, a negative one, in which they seek to show that Olson's argument does not prove what it seems to prove; and a positive one, in which they reformulate the problem to produce significantly different results. It is not possible to summarize here their criticism of Olson's formal argument. ${ }^{20}$ Their reformulation of the problem, however, is the foundation on which they develop a theory of political leadership, which is in turn the basis for what Frohlich and Oppenheimer have to say about international politics.

To simplify, they argue that each person's incentive to contribute depends upon what he expects others to do, or, more precisely, how likely he thinks it is that the aggregate contributions of others will fall short of what is required by various amounts. If there were only one amount by which the contributions of others might fall short, an individual could decide whether the contribution required of him was worth its cost. However, since contributions may fall short by varying amounts, each person must estimate the likelihood of each level of deficiency, and then, if he is rational, choose that level of contribution on his own part that will maximize the expected value to him of contributing. What is crucial, in other words, is the ability of people to formulate expectations about the behavior of

\footnotetext{
${ }^{20}$ Frohlich and Oppenheimer, pp. 71-82. See also the book by Frohlich, Oppenheimer, and Young.
} 
others. Since, on the basis of some possible expectations, many individuals would have an incentive to contribute, there is no reason to assume a priori that everyone will always expect that others will not contribute. Nor is there any reason, assuming no more than rational, self-interested behavior, to believe that the ability of people to develop positive mutual expectations is a function of the number of persons concerned.

It may be worth pointing out that this statement of the problem assumes that the widespread equation of the collective goods problem with the prisoners' dilemma is incorrect. For it is characteristic of the prisoners' dilemma that, no matter what expectation one formulates of the choice of others, one prefers not to cooperate. This may be true of many collective goods situations. But the definition of a collective good is also consistent with games in which cooperative strategy choices lead to equilibrium outcomes. However, the distribution of the payoffs varies depending on which of the possible strategy combinations is chosen; in other words, the game includes a bargaining problem. ${ }^{21}$

The work of Frohlich, Oppenheimer, and Young, therefore, is based on the assumption that people are able to make subjective estimates of the probabilities associated with varying levels of contributions from other people and decide whether to contribute accordingly. At the heart of their theory of politics is the notion that these expectations can be influenced. And if that is granted, they argue, then individual persons can gain some private advantage by concerting the expectations of others and soliciting their contributions toward the provision of some collective good. In other words, the fact that people do have an incentive to contribute when they are able to concert their expectations of each other's behavior provides an opportunity for the development of political leaders; and the possibility of private gain from these contributions, along with the benefit derived from whatever collective good can then be supplied, provides potential leaders with the incentive to exploit this opportunity. ${ }^{22}$

Thus their reformulation of the collective goods problem leads them directly to an analysis of political leaders as persons who, partly or entirely motivated by private gain, create political organizations

\footnotetext{
${ }^{21}$ For two efforts to interpret collective goods situations as prisoners' dilemmas, see James Buchanan, The Demand and Supply of Public Goods (Chicago: Rand McNally \& Co., 1968), pp. 88-91; and Russell Hardin, "Collective Action as an Agreeable n-Prisoners' Dilemma," Behavioral Science 16 (September 1971): 472-81.

${ }^{22}$ Compare Schelling's comment, "The coordination game probably lies behind the stability of institutions and traditions and perhaps the phenomenon of leadership itself." Thomas Schelling, The Strategy of Conflict (New York: Oxford University Press, 1963), p. 91.
} 
by soliciting the contributions of others, or taxing others, in order to raise the resources necessary to supply collective goods. In the book under discussion, this provides the basis for an analysis of the development of political organizations, political competition, the modification of political competition through agreement on collective decision rules, and taxation. In their dissertation, Frohlich and Oppenheimer extend this analysis, by modifying the assumption of a pure collective good, to include discussion of the formation of exclusive political groups and the relations among them, along with a richer and more interesting analysis of taxation. Thus they are able to develop the basis for an individualistic theory of domestic and international politics that is not tied to assumptions about the political decision rules of any particular society, although analysis of any particular society would require that the nature of the rules operative there be taken into account.

Their analysis of political organizations is built on a discussion of the utility functions of political leaders and political followers. The utility of political followers is taken to be equal to the expected value of contributions to political leaders and their competitors, minus the value of donations and taxes, plus the value of any "contracts" received from the leader for helping produce the good or maintain the leader's organization. The utility of political leaders is taken to be equal to the value of the good supplied, plus the value placed on donations and taxes collected, plus any pleasure derived from leading a political organization, minus the costs of supplying the goods and maintaining the organization. The analysis proceeds on the basis of the standard assumption that each seeks to maximize these respective values.

This assumption leads to some interesting questions of efficiency for political leaders. These include, for example, the effect of taxes on followers' incentives to make contributions, the relation between an organization that collects taxes and one that collects donations, the relation between organizations that raise revenue and those that supply such collective goods as internal security, complementarities that may exist between various possible collective goods and which influence the leader's decision about what goods to provide, and so forth.

In the absence of competition, the operation of a political organization is likely to be extremely advantageous when taxation is possible. However, this fact, coupled with the dissatisfaction of political followers, offers a powerful incentive for the rise of a competitor. The analysis offered of political competition derives, in part, from the contrast between collective and private goods. Because 
private goods are consumed exclusively rather than collectively, the quantity of goods demanded increases greatly as the number of consumers increases. The quantity of collective goods consumed does not increase so rapidly with increases in the number of consumers; however, the revenue that can be collected for supplying them does increase rapidly. Therefore, collective goods can be extended to larger and larger numbers of consumers at little or no marginal cost but for significant marginal revenue. Thus there is little opportunity for sharing the market for collective goods, and potential competitors must either seek to supply goods that are not substitutes for the goods supplied by the incumbent or seek to replace him.

In seeking to replace him, of course, a political competitor seeks to put together a rival political organization, and this process can be analyzed in much the same way as the creation of the incumbent's organization. However, the existence of an opposition creates a situation that is different for both leaders and followers from the noncompetitive situation. It is, among other things, a situation that is much more risky for both leader and opposition. This risk can be reduced, however, by collusion between leader and opposition, which may take the form of agreement on a set of collective decision rules. Such rules would have the effect of guaranteeing the provision of some collective goods no matter who wins.

Moreover, because of its effects on the behavior of the incumbent, opposition itself can be a collective good; and it is possible for an opposition leader to make a profit so long as the probability of his becoming leader, though small, is positive. Hence the role of opposition leader becomes a profitable one entirely independently of the fact that it may be a route to the leadership. And it is rational for followers in these circumstances to contribute to both the political leader and his opponents. Thus the utility of followers now becomes a function of both leadership and the opposition; and a follower may contribute to either or to both, either to change the probability of their success or in exchange for alterations in their proposed programs.

There are a number of important consequences of this analysis. One is that, unlike Downsian politicians, political leaders do not always seek to maximize their chances of holding office. They may elect to become a perpetual opposition, or they may choose to maximize their gains in one time period at the cost of losing office in another. Moreover, a link is established between the analysis of political leadership and competition and the development of collective decision rules.

Finally, although so far no mention has been made of international politics, it should already be clear that there is an important 
similarity between domestic and international political conflict: in both cases, political leaders who are opponents are rival suppliers of collective goods. It seems a fair inference that rivalry can exist between allies as well as between enemies-that, for example, in supplying nuclear deterrence (a collective good) to citizens of other countries, a government may not only be assisting the governments of those countries but may also be competing with them. Before these points can be pursued, however, the rationale for the development of exclusive political communities must be established.

Clearly, in talking about exclusion one has already altered one of the defining characteristics of a pure collective good: nonexclusiveness. Moreover, one of the incentives for exclusion derives from a lack of purity in the other dimension that distinguishes these goods: nonrivalness of consumption. If the addition of consumers above a certain number begins to diminish the consumption units available to others, then there is some reason to restrict consumption. But there are other possible reasons as well. One is derived from the problem of coordinating expectations, and the addition of new members may make that problem more difficult. This could be because of the effects of history or tradition on the mutual expectations of some members but not others, or because of the advantage of maintaining some degree of homogeneity with respect to the evaluation of the collective goods supplied. ${ }^{23}$ Another incentive may be diminishing returns as the scale of production of collective goods is increased. Once the decision to exclude has been made, it is possible either to exclude groups collectively or to provide access to the collective goods individualistically.

On the basis of these distinctions, Frohlich and Oppenheimer developed in their dissertation an analysis of group competition, the distribution of political programs, and taxation. What they have to say is complex, and only a hint can be given here of their argument.

${ }^{23}$ Compare the following comments by Karl Deutsch: "Insofar as members of a stable political community must be able to expect more or less dependable interlocking, interchanging, or at least compatible behavior from each other, they must be able ... to predict one another's actions. ... Examples of such predictions . . . might include John C. Calhoun's opposition to the incorporation of any additional large parts of Mexico into the United States, on the grounds that the Mexican people could not be expected to be assimilated by the Americans; and the alleged deliberate limitation by Bismarck, according to Graham Wallas, of his intended German Empire 'by a quantitative calculation as to the possibility of assimilating other Germans to the Prussian type. He always opposed the inclusion of Austria, and for a long time the inclusion of Bavaria, on the ground that while the Prussian type was strong enough to assimilate the Saxons and Hanoverians to itself, it would fail to assimilate Austrians and Bavarians.' " Karl Deutsch, Political Community at the International Level: Problems of Definition and Measurement (New York: Doubleday, 1954), pp. 53-54. 
For example, they discuss the choice faced by persons excluded from access to collective goods of whether to seek to acquire access collectively or individually. The larger the number of people who acquire access individually, the smaller the chances of those remaining to do so collectively. This discussion leads to some interesting comments about the Black Power movement in the North as a means of discouraging blacks from gaining access to collective goods individually and of encouraging them to turn their efforts toward group action. Their analysis of taxation incorporates the assumption that the more people evade, the more difficult it is to apply sanctions. Thus, they are led to a discussion of evasion and the organization of rebellion as alternatives to the payment of taxes, in which an individual's decision about whether to evade is based on a prediction of the probable number of other evaders.

Another option open to a dissatisfied person is migration to another political community. In discussing an individual's decision on whether to migrate, and the reaction to this on the part of political leaders, Frohlich and Oppenheimer provide an explicit, although not very extensively developed, treatment of at least one form of transnational relation. Although economic factors may be involved, their discussion focuses entirely on the political factors. A person's decision about whether to migrate is shown to be influenced by whether he is a tax evader or a taxpayer, and whether he migrates alone or collectively. The reactions of his own leader and the leader of the community to which he seeks to migrate will be influenced by the same factors.

From the point of view of the leader, important considerations are the impact of group migration on the information other followers have about goods available elsewhere and the effects of group migration on the ability of the remaining dissenters to coordinate their actions. These considerations may lead him to prefer to prevent group migrations even of tax evaders and disloyal subjects, while he may permit them to migrate individually. However, if group migrants can be used as scapegoats, their departure may be used to convince dissidents who remain that they cannot expect many other people to resist and that further resistance on their part is therefore futile. Frohlich and Oppenheimer's discussion calls to mind the policies of Cuba, East Germany, and the Soviet Union toward politically motivated migration in recent years.

Frohlich and Oppenheimer's more elaborate treatment of taxation leads them also to a reformulation of the nature of group competition, which takes into account the attitudes of rival leaders toward evaders of each other's taxes. Their analysis is clearly relevant to an 
analysis of insurgency. It is also relevant to the question of when do opponents have an incentive to cooperate in maintaining a common tax mechanism and therefore to segregate the collection of taxes from political competition-a crucial aspect of political development.

The implications of all this for the study of international politics are only briefly touched on by Frohlich and Oppenheimer. In attempting to state the main distinguishing feature of their analysis, they say :

It should be noted that the usual distinction between international and domestic politics is broken down in the current formulations. The political behavior of the members with regard to their domestic considerations is seen to be a function of the nature of the foreign relations which exist. The foreign policies of the leader, far from being those which are solely motivated by his interest in the viability of the state or social structure in question, [are] explained in terms of his own profit motivation. These considerations mean that the relationships between national interests and foreign policies are at best indirect. . . . The incentives for the politician to pursue one foreign policy rather than another will be seen in terms of such . . . considerations as the distributions of resources and valuations in the society, and how they bear on the overall profitability of his role. ${ }^{24}$

Perhaps some of the flavor of this sort of analysis can be indicated by another quotation:

One of the interesting consequences which follows immediately from this perspective is the leader's interest in maintaining a feeling of chauvinism in his membership. That is, in order to protect the member's appreciation of the services which he receives from the leader, the leader will be interested in having the member regard the alternative leaders from any foreign society as inferior. . . . Furthermore, the greater the difference a member feels he can make in determining the outcome of the competition, the less motivation he need receive from differences in valuation of the two sides to engender the same level of supportive behavior. The greater the feeling of inefficacy, the greater must be the utility differential between the two outcomes, to engender the same behavior. Within the same society, the leadership would, therefore, always try to insure that the disenfranchised and inefficacious members become the staunchest jingoists. ${ }^{25}$

${ }^{24}$ Frohlich and Oppenheimer, pp. 360-61. In another article, Frohlich and Oppenheimer have attempted to draw some further implications of their work for the study of international politics. See Norman Frohlich and Joe A. Oppenheimer, "Entrepreneurial Politics and Foreign Policy," World Politics 24 (Spring 1972) supplement: 151-78.

${ }^{25}$ Frohlich and Oppenheimer, "An Entrepreneurial Theory," pp. 357-58. 
Since this essay began with a discussion of what I have termed the state-as-actor and state-centric assumptions, perhaps some further implications of their work of relevance to each of these assumptions can be drawn.

The state-as-actor assumption, of course, is abandoned entirely. Instead, the world consists of individual persons, some of whom are political leaders supplying collective goods to their followers. These leaders are motivated primarily by the private gain to be derived from this activity. Naturally they will have some interest in protecting their opportunity to engage in it from foreign competition. However, there is no reason to assume that they will be interested in minimizing the probability of being taken over by some foreign political competitors, since there is no reason to assume a priori that such a goal would maximize their own profits.

The value that followers place on diminishing the probability of successful attack is a function of the difference between the value they place on the stream of goods received from domestic leaders and their competitors and the value they place on the goods supplied by the enemy. There is, again, no reason to assume they wish to minimize the probability of defeat, since the value of doing so may be less than the cost. Moreover, individual followers are likely to differ in the value they place on security, even if they all agree in preferring to maintain the autonomy of their own society. However, since it is extremely unlikely that the taxes they pay match exactly the benefits they receive in this respect, and since in any case everyone has an interest in trying to shift the burden of supplying collective goods onto others, there is likely to be significant conflict over defense policyagain, even if everyone agrees that their own society is preferable to the enemy's. Moreover, those with the strongest interest in defense will seek to manipulate the incentives that those with the weakest have to contribute resources toward providing it. The enemy will also seek to manipulate these incentives, however; and, therefore, among the strategy choices open to enemies will be those that influence opponents' followers' incentives to support their opponents.

Moreover, efforts on the part of leaders to influence their external environments can be expected to be relevant to the provision of other collective goods besides security. These goods can also be assumed to be supplied to some persons and not to others; and those to whom they are supplied can be expected to differ in their evaluations of them. If efforts to increase security either are complementary to the supply of these other goods or competitive with them, then these efforts will influence the value that consumers place on the supply of increments of security and will, therefore, add to the 
potential for conflict over security policies. Since these relationships will affect the profitability of various foreign policy mixtures for political leaders, the likelihood that they exist diminishes further any reason to assume an interest in maximizing security on the leaders' part.

The same set of assumptions imply, of course, that the customary state-centric assumption is also abandoned entirely. Not only is attention called to some possibly important transnational relations (e.g., politically motivated migration and international civil war), but explaining the absence of transnational relations, or the presence of effective geographical boundaries between exclusive political communities, also becomes a problem. Thus, the political incentives for maintaining separate political systems, for remaining in one's own, and for seeking to protect it from foreign competitors are subjected to explicit treatment. Furthermore, the very concept of a collective good calls attention to an important type of transnational relationthe supply of collective goods across national boundaries. Because such goods are supplied to persons and not to governments, there is an important sense in which all international political relations, including both conflict and alliance, may involve transnational relations. And it may be that some forms of nationalist behavior on the part of political leaders can be explained, in part, as the result of an effort to insulate their communities from rival suppliers abroad or to distinguish the goods they supply from those that are the spillover effects of the decisions of foreign governments.

Finally, and perhaps most important, these assumptions help focus our attention on the possibility of transnational political organization. In a world in which some collective goods can only be supplied optimally, or at all, at the international level but in which not many persons wish to create international governments, or merge their own communities with others, attention must be focused on the problem of coordinating the decisions of independent governments. This is a situation in which persons in one country may have an incentive to cooperate with persons in others to influence the decisions of their respective political leaders.

Moreover, one must not think that doing so requires a very elaborate or visible international organization, since the heart of the problem of collective action is the coordination of expectations. It is entirely possible that the bulk of the organization required for such transnational efforts may be national in structure. The question to be asked is this one: To what extent is political action in country A influenced by the belief that persons in country B are acting similarly? It seems to me entirely possible that the answer to that question may 
even now be "quite a lot." If so, it is likely to be, for example, a more significant part of the explanation of the relations between the US and Great Britain than the relations between the US and Japan-a fact that may in turn influence the nature of intergovernmental relations between the two countries. Of course, bureaucrats can engage in such transnational relations as well as anyone else, and do so, perhaps, with somewhat broader interests in mind than the bureaucratic ones to which Allison's model calls our attention; but others may also be well placed to do so. ${ }^{26}$

V

Thus the literature on collective goods, represented here by the work of Frohlich, Oppenheimer, and Young, raises some questions about the relation between domestic political conflict and international politics that the bureaucratic politics literature underplays. It suggests that one must take seriously the possibility of serious social conflict even over questions of defense policy. It also calls our attention to types of transnational relations, and to motives for developing or limiting them, that the bureaucratic politics literature does not emphasize. However, because bureaucracies do not inhabit the world created by Frohlich, Oppenheimer, and Young, it would be difficult to say what relations might exist between the propositions of these two bodies of literature. Even Anthony Downs, who has talked about both, has talked about them separately, and not tried to integrate them.

This is, in part, the result of concentrating on different questions. However, as Allison's discussion of his Model II reminds us, underlying this difference in emphasis may be differences in assumptions about the behavior of individuals and disagreements about how one is to understand the behavior of individuals under conditions of uncertainty. Thus any effort to deal simultaneously with the questions raised by these two bodies of literature must come to terms with this problem in some explicit fashion. The notion of subjective probability, by which Frohlich, Oppenheimer, and Young deal with it, undoubtedly exaggerates the consistency of behavior of most persons; and it leaves unclear what regularities, if any, might characterize subjective probability estimates. ${ }^{2 \pi}$ However, most of the literature about politics fails to treat this problem explicitly at all. In light of the conventional wisdom on this subject in political science, it is odd

\footnotetext{
${ }^{20}$ Work in progress by Keohane and Nye is directly relevant to these suggestions.

${ }^{27}$ For some anecdotal evidence that most actual behavior falls short of these assumptions, see Raiffa, pp. 110-14.
} 
that the main explicit treatments of the implications of uncertainty for political behavior are by Charles Lindblom and Anthony Downs, both economists; and it is also odd that in one of the few discussions of the issues by a political scientist, Graham Allison has left unclear the nature of the assumptions underlying the most influential part of his book-the part outlining the bureaucratic politics paradigm. ${ }^{28}$

Clearly what is at issue here is not merely differences in emphasis or even in underlying assumptions but a difference of method. What is at stake is, in part, an implicit disagreement about the rate of exchange between deductive explicitness and empirical relevance at this stage in the development of political science. The three works considered here represent three distinct points on a possible continuum of views on this question. On the basis of a suspicion that some things are happening in the world that are overlooked by the prevailing orthodoxy, Keohane and Nye have organized a systematic search to unearth instances of what has been overlooked and have suggested some changes in our concepts necessary to accommodate what they have found. Allison has tried to make explicit the basic concepts and some of the assumptions underlying three bodies of literature of relevance to foreign policy decisions, without producing a complete formalization of any of them. And Frohlich, Oppenheimer, and Young have tried to develop a deductive theory.

If one compares these works on the basis of the explicitness of what they have to say and the grounds for saying it, there are more problems with the first than with the last, with Allison's book somewhere in between. If one compares them on the basis of their immediate relevance to, say, international relations as we customarily define it, however, then the advantages run in the other direction. Part of the problem lies in what has to be left out to achieve deductive rigor and what it would take to put it back in, and part lies in assumptions whose descriptive accuracy can be questioned.

In spite of these differences in method, these works represent an interesting and important convergence of views. Certainly none of them offer a full-blown treatment of international politics. Nonetheless, it seems to me that enough has been said to indicate that some prevalent assumptions have the effect of excluding some interesting possibilities from systematic investigation and to cast some doubt on these assumptions. Once governments are seen to be much more primitive actors than many people assume, and individuals, whether within governments or outside them, are seen to be significant par-

${ }^{28}$ Downs, An Economic Theory of Democracy, Parts II and III; Downs, Inside Bureaucracy, especially chapter 14; Charles Lindblom and David Braybrooke, $A$ Strategy of Decision (New York: The Free Press, 1963). 
ticipants in international politics whose interests and actions cannot simply be identified with those of governments, then a number of events may begin to look different. Moreover, it may become possible for academic students of international politics to treat analytically, rather than polemically, many of the theoretical issues raised by the Left. However, to do so will require careful, explicit, and simultaneous attention to alternatives to both the state-centric and state-as-actor assumptions. 